\title{
Associação da deficiência de ácido fólico com alterações patológicas e estratégias para sua prevenção: uma visão crítica
}

\author{
Association between folic acid deficiency \\ and disease and prevention \\ strategies: a critical view
}

Sofia Kimi UEHARA'

Glorimar ROSA²

RE S U M O

A deficiência de ácido fólico está associada às doenças crônicas não-transmissíveis, complicações na gestação e doenças neurodegenerativas. Objetivou-se discutir o papel do ácido fólico na prevenção de doenças, os aspectos epidemiológicos de sua deficiência, fortificação dos alimentos e suplementação medicamentosa. Realizou-se levantamento bibliográfico, consultando as bases de dados para a obtenção dos artigos completos: MedLine, SciELO, PubMed, Highwire Press e Science Direct. Foram selecionados estudos realizados com seres humanos publicados entre 2004 e 2010. O ácido fólico é importante para as reações de metilação do ácido desoxirribonucléico, prevenção da hiper-homocisteinemia e atua como antioxidante. A deficiência dessa vitamina é descrita em adolescentes, mulheres em idade fértil, gestantes e em idosos. Seu alcance pela dieta é difícil, sendo necessária a inclusão de alimentos fortificados ou suplementos. É importante avaliar o estado nutricional de ácido fólico dos indivíduos antes e após a adoção dessas estratégias, de modo a gerar subsídios para elaboração de medidas governamentais mais adequadas e eficazes. Destacamos ainda a necessidade da reeducação nutricional para a população brasileira a fim de aumentar o consumo de alimentos fontes de ácido fólico.

Termos de indexação: Ácido fólico. Alimentos fortificados. Doenças crônicas não-transmissíveis. Suplementação dietética.

\section{A B S T R A C T}

Folic acid deficiency is associated with non-communicable chronic diseases, pregnancy-associated complications and neurodegenerative diseases. The objective of this paper was to discuss the role of folic acid in disease

\footnotetext{
1 Universidade Federal do Rio de Janeiro, Instituto de Nutrição Josué de Castro, Programa de Pós-Graduação em Nutrição. Rio de Janeiro, RJ, Brasil.

${ }^{2}$ Universidade Federal do Rio de Janeiro, Instituto de Nutrição Josué de Castro, Departamento de Nutrição e Dietética. Av. Carlos Chagas Filho, 373, CCS, Bloco J, $2^{\circ}$ andar, Sala 25, Cidade Universitária, 21941-902, Rio de Janeiro, RJ, Brasil. Correspondência para/Correspondence to: G. ROSA. E-mail: <glorimar@nutricao.ufrj.br>.
} 
882 S.K. UEHARA \& G. ROSA

prevention, the epidemiological aspects of its deficiency and food fortification and supplementation. Articles were searched in the following databases: MedLine, SciELO, PubMed, Highwire Press and Science Direct. Only original studies with humans published between 2004 and 2010 were included. Folic acid is important for DNA methylation and prevention of hyperhomocysteinemia. It also presents antioxidant activity. Folic acid deficiency has been described in adolescents, women of childbearing age, pregnant women and the elderly. It is difficult to meet the folic acid requirement with diet alone, so fortified foods and supplements are necessary. It is important to assess folic acid levels before and after the implementation of such strategies to enable the development of better and more effective public strategies. It is also important to provide nutrition education for the Brazilian population for them to increase their consumption of dietary sources of folic acid.

Indexing terms: Folic acid. Food fortification. Non-transmissible chronic diseases. Dietary supplements.

\section{N T R O D U Ç Ã O}

Lucy Wills, em 1931, encontrou o Ácido Fólico (AF) em extrato de leveduras e demonstrou ser eficiente no tratamento da anemia macrocítica tropical em mulheres indianas no final da gestação. Mais tarde, essa vitamina passou a ser denominada ácido fólico pelo fato de ter sido isolada das folhas de espinafre'.

Os tetra-hidrofolatos reduzidos são necessários para o processo de divisão celular e para assegurar a síntese do S-adenosilmetionina (SAM), o maior doador celular de grupamento metil para as reações de metilação².

A metilação do ácido desoxirribonucleico (DNA) está relacionada com o controle da expressão gênica e manutenção da conformação e integridade dos cromossomos ${ }^{2}$. As reações de metilação também são vitais para prevenir o aumento das concentrações plasmáticas da homocisteína (Hcy), quadro denominado de Hiper-homocisteinemia (Hhcy), considerado um marcador das Doenças Cardiovasculares (DCV) ${ }^{3,4}$.

O AF presente nos alimentos está sob a forma de poliglutamato, que deve ser convertido em monoglutamato antes de ser absorvido. Por sua vez, ele na forma de suplemento medicamentoso, é mais estável e se encontra na forma de monoglutamato, rapidamente absorvida. Assim, a biodisponibilidade do AF dietético para a absorção intestinal é de $60 \%$, enquanto para o AF dos suplementos ou alimentos enriquecidos é de $98 \% \%^{5}$. Essa diferença resulta em controvérsias quanto às estratégias para recuperação e prevenção da deficiência deste ácido, que por sua vez estaria associada à diferentes situações patológicas.

Nosso objetivo foi discutir o papel do AF na prevenção de doenças, os aspectos epidemiológicos de sua deficiência e a fortificação dos alimentos e suplementação medicamentosa com AF.

\section{MÉTODOS}

O levantamento bibliográfico foi realizado por meio de consulta às seguintes bases de dados eletrônicas: MedLine, SciELO, PubMed, Highwire Press e Science Direct. A busca retrospectiva se limitou aos artigos científicos indexados, originais como estudos clínicos randomizados e não randomizados, transversais, prospectivos, de coorte e de base populacional, que envolveram seres humanos e que foram publicados entre 2004 e 2010, escritos nas línguas inglesa ou portuguesa. Utilizou-se a combinação das seguintes palavras-chave: ácido fólico, cobalamina, homocisteinemia, defeitos do tubo neural, doenças crônicas não transmissíveis, gestação, fortificação de alimentos e polimorfismos da metilenotetra-hidrofolato redutase.

\section{Absorção e aspectos fisiológicos do ácido fólico}

O AF da dieta inicialmente é convertido a monoglutamatos pela ação da enzima pteroilpoliglutamato hidrolase (folato conjugase ou glutamato carboxilase II), dependente de zinco, localizada na membrana da borda em escova jejunal. Esse processo é ativo saturável e dependente do pH (pH ótimo de 6,5 a 7,0) e sódio. Entretanto, 
quando presente em altas concentrações, o AF atravessa diretamente a parede dos enterócitos sem sofrer modificações. Antes de alcançar a circulação portal, é reduzido a tetra-hidrofolato e também submetido à metilação ou formilação nos enterócitos ${ }^{1}$. O monoglutamil folato é transportado pela veia porta para o fígado, o principal sítio de estocagem e processamento dos compostos de AF, para posterior distribuição para os tecidos e bile, possibilitando o seu reaproveitamento pelo organismo através da circulação entero-hepática ${ }^{5}$.

No plasma, o 5-metil tetra-hidrofolato (5-metil THF) é a principal forma de AF circulante. Na circulação, o 5-metil THF encontra-se ligado principalmente à albumina. Contudo, uma pequena quantidade se liga à proteína ligante de folato de alta afinidade. O transporte de AF para o interior das células, nos rins e na placenta ocorre por meio de proteínas ligantes, associadas à membrana, que agem como receptores e que facilitam o transporte celular do AF. Uma vez no interior da célula, o 5-metil THF é demetilado e convertido em tetra-hidrofolato-poliglutamato pela ação da enzima folilpoliglutamato sintase. Antes de alcançarem a circulação, os poliglutamatos são reconvertidos em monoglutamatos pela enzima poliglutamato hidrolase ${ }^{2}$.

Em humanos, estima-se que o conteúdo total de AF seja de aproximadamente 34-68 $\mu \mathrm{mol}$ (15-30mg), encontrando-se cerca de 50\% no fígado. Nos eritrócitos, também encontramos quantidades de AF cujas concentrações são maiores que no plasma. Nessas células, o AF encontra-se na forma de poliglutamatos ligados à hemoglobina. Não se sabe se essa ligação estaria regulando a atividade da hemoglobina ou se seria apenas uma forma de armazenamento do $\mathrm{AF}^{1}$.

Wright et al. ${ }^{6}$ reexaminaram artigos científicos abrangendo os mecanismos de absorção do AF e sugerem que o fígado, e não as células absortivas do intestino delgado, seria o primeiro sítio de absorção do AF. Considerando-se que o fígado teria uma fraca capacidade de promover a redução do $\mathrm{AF}$, como consequência teríamos impor- tantes implicações quanto ao uso de suplementos e alimentos fortificados com essa vitamina, o que resultaria num aumento do AF não metabolizado na circulação sistêmica, podendo acelerar o declínio cognitivo em idosos, maior probabilidade de complicações gestacionais, diferentes casos de cânceres e doenças cardiovasculares. Assim sendo, tanto a fortificação de alimentos quanto o uso de suplementos com AF seriam benéficos para alguns grupos populacionais e deletérios para outros, como, por exemplo, os idosos, que, pelo fato de já apresentarem deficiência de cobalamina, poderiam ter um maior comprometimento da função cognitiva ${ }^{6}$.

\section{Ácido fólico e sua associação com as doenças crônicas não-transmissíveis}

O estado adequado do AF é fundamental para a prevenção das Doenças Crônicas Não-Transmissíveis (DCNT), defeitos congênitos, complicações gestacionais e outras enfermidades. Contudo, é importante destacar que existe uma interação entre o $A F$, cobalamina, piridoxina, riboflavina e zinco (Figura 1). A cobalamina e o zinco atuam como cofatores da enzima metionina sintase que participa da remetilação da hcy em metionina. Uma outra via de remetilação da hcy está destinada ao fígado e é catalisada pela enzima betaína-homocisteína metiltransferase, que é dependente de zinco. As enzimas cistationina- $\beta$ -sintase (C $C S S$ ) e gamacistationase, ambas envolvidas na excreção de hcy, são dependentes de piridoxina e cobalamina respectivamente. A riboflavina é requerida pela enzima Metilenotetra-Hidrofolato Redutase (MTHFR), que converte o 5,10 metileno-tetra-hidrofolato em 5-metil tetra-hidrofolato, o doador do grupo metil para a reação de remetilação da hcy em metionina².

Em geral, a suplementação simultânea de AF, piridoxina e cobalamina promove a redução da homocisteinemia. Contudo, isoladamente, a suplementação com AF parece ser mais eficiente. A dose exata dessas vitaminas necessária para o tratamento da Hhcy ainda não foi determinada. 
884 | S.K. UEHARA \& G. ROSA

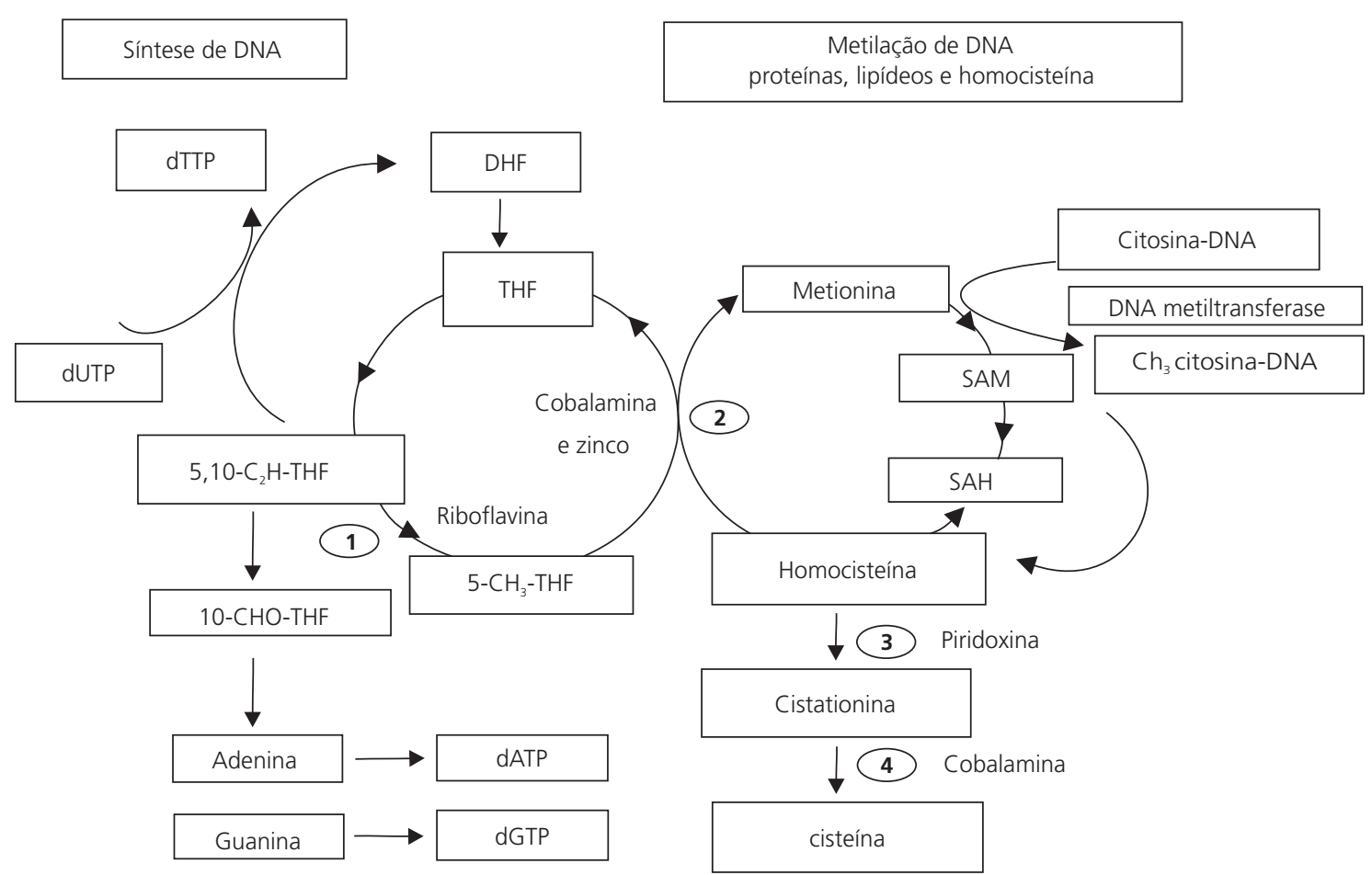

Figura 1. Ciclio do ácido fólico com ênfase nas duas maiores funções desta via no metabolismo celular: síntese de DNA e fornecimento de grupos metil para as reações de metilação do DNA, proteínas, lipídeos e homocisteína.

Nota: (1) metilenotetra-hidrofolato redutase; (2) metionina sintase; (3) cistationina- $\beta$-sintase; (4) $\gamma$-cistationase.

DHF: dihidrofolato redutase; THF: terahidrofolato; SAH: S-adenosilhomocisteína; SAM: S-adenosilmetionina; 5, 10-C ${ }_{2} \mathrm{H}-\mathrm{THF}$ : 5, 10 metilenotrtrahidrofolato; 5- $\mathrm{CH}_{3}$-THF: 5-metil tetrahidrofolato; dUTP: 2'desoxiuridina 5'trifosfato; dTTP: 2'desotimidina 5'trifosfato; dATP: 2'desoxiadenosina 5'trifosfato; dGTP: 2'desoxiguanosina 5'trifosfato; DNA: ácido desoxirribonucleico.

Considera-se que a dose diária mínima de AF que apresenta eficácia máxima na redução da homocisteinemia seja de aproximadamente $400 \mu{ }^{1}$.

Devido à menor biodisponibilidade do $\mathrm{AF}$ dos alimentos, é improvável que a dieta, utilizada isoladamente, seja suficiente para aumentar a concentração plasmática de AF e reduzir a concentração de hcy. Bazzano ${ }^{7}$ demonstrou que o AF proveniente da suplementação promoveu redução da homocisteinemia e aumento do folato plasmático; ao contrário do que acontece com o AF presente naturalmente nos alimentos. Embora esse autor tenha observado que a ingestão de alimentos ricos em AF não tenha sido eficaz no tratamento da Hhcy, Pintó et al. ${ }^{8}$ verificaram que o consumo de dieta contendo $500 \mu \mathrm{g}$ de $\mathrm{AF}$, provenientes da ingestão de frutas, hortaliças, leguminosas e cereais enriquecidos, foi tão eficiente quanto à suplementação com $500 \mu \mathrm{g} /$ dia de $\mathrm{AF}$ na redução da homocisteinemia ${ }^{8}$.
Segundo Morris et al. ${ }^{9}$, o AF e a cobalamina desempenham importante papel na manutenção e reparação do tecido ósseo, uma vez que estão envolvidos na doação de grupamento metil para a síntese de DNA. O AF também parece estimular a atividade dos osteoblastos: células que sintetizam e secretam a matriz orgânica do osso. As baixas concentrações de AF em eritrócitos estão associadas a uma menor densidade mineral óssea ${ }^{9}$.

O Estresse Oxidativo (EO) e o acúmulo de radicais livres estão relacionados com os distúrbios neurodegenerativos, uma vez que promovem peroxidação lipídica excessiva, resultando na degeneração neuronal ${ }^{10}$. Adicionalmente, o EO tem sido associado com: a) resistência à insulina $(\mathrm{RI})^{9,11}$, contribuindo para o desenvolvimento da síndrome metabólica e do diabetes mellitus tipo 2 , b) lesões no DNA, resultando em mutação gênica ${ }^{12}$, c) pro- 
cessos inflamatórios ${ }^{13}$, d) disfunção endotelial que precede o desenvolvimento da aterosclerose ${ }^{10} \mathrm{e}$ e) infertilidades masculina e feminina ${ }^{14}$.

Segundo a literatura científica, existe uma relação entre a deficiência de AF, a Hhcy e o EO ${ }^{15}$. Concentrações elevadas de hcy podem ter um efeito pró-oxidante, pois reduzem a expressão da glutationa peroxidase e favorecem a produção de Espécies Reativas de Oxigênio (ERO). No plasma, a hcy é rapidamente oxidada, originando as ERO, tais como homocistina e homocisteína tiolactona ${ }^{16}$. Pelo exposto, o AF pode ser considerado um antioxidante, uma vez que previne a Hhcy, o que é confirmado pela literatura. O AF inibe a peroxidação lipídica e protege as membranas celulares e o DNA dos danos causados pelos radicais livres ${ }^{14}$.

Embora as ERO estejam associadas com efeitos negativos à saúde, elas são necessárias para a ocorrência de várias reações do organismo, tais como apoptose, fagocitose e reações de detoxificação. O sistema antioxidante remove apenas o excesso de ERO, mantendo as concentrações necessárias para as reações citadas anteriormente. $O$ equilíbrio entre os antioxidantes e as ERO é importante para o adequado funcionamento celular e o excesso pode inibir a apoptose e prejudicar a ação de fármacos empregados no tratamento do câncer, agindo na indução da apoptose ${ }^{12}$.

Concentrações elevadas de hcy no cérebro estão associadas com risco aumentado de doença e lesão cerebrovascular e neurotoxicidade ${ }^{10}$. Vários são os mecanismos propostos para explicar essa relação, tais como: prejuízo da vasodilatação endotélio-dependente, inibição da enzima óxido nítrico sintetase, promoção da peroxidação lipídica, prejuízo do potencial antioxidativo celular, aumento da agregação plaquetária, inibição dos anticoagulantes naturais, ativação da apoptose neuronal e EO aumentado ${ }^{10}$. Tchantchou \& Shea ${ }^{17}$ verificaram associação entre a deficiência do AF e a atrofia do córtex cerebral em idosos portadores da doença de Alzheimer. O AF exerce importante papel no desenvolvimento do sistema nervoso central, no metabolismo de neurotransmissores e na preservação e integridade da memória com o avanço da idade ${ }^{17}$.

Desse modo, recomenda-se que os pacientes infartados, os portadores de doença vascular cerebral, doença de Alzheimer ou deficit cognitivo leve sejam investigados para a possível presença de Hhcy e deficiência de $A F^{10}$.

A deficiência de AF tem sido apontada como fator de risco para o câncer, em especial o colorretal. A essencialidade dessa vitamina na transferência de grupamentos metil para as reações de metilação seria a melhor justificativa para essa associação. A hipometilação do DNA, danos na estrutura do DNA e do processo de reparação do DNA podem ter papel fundamental na carcinogênese. Além disso, os distúrbios no metabolismo do DNA estão envolvidos com as alterações na expressão de genes supressores de tumores e dos proto-oncogenes. A Hhcy tem sido associada a risco aumentado para câncer ${ }^{18}$.

A associação entre o polimorfismo C677T no gene MTHFR e o câncer é controversa. O estado do AF parece ser o principal determinante da relação entre o polimorfismo C677T no gene da MTHFR e o câncer. O risco aumentado de câncer em indivíduos com o polimorfismo e depleção do $\mathrm{AF}$ pode estar associado à menor disponibilidade de metiltetra-hidrofolato para as reações de metilação do DNA ${ }^{18}$. Estudo in vitro demonstrou que a deficiência do ácido fólico diminuiu a expressão do gene $P 53$, que está envolvido com a reparação do DNA. Esse gene codifica a fosfoproteína $53 \mathrm{Kda}$, que exerce importante papel no controle do ciclo celular. Após a lesão do DNA, essa fosfoproteína é capaz de limitar a proliferação celular, seja ativando a apoptose ou retardando o ciclo celular para permitir a reparação do DNA ${ }^{12}$.

As alterações no sistema imunológico têm sido associadas com o desenvolvimento, progressão e reincidência de cânceres. As células natural killer são capazes de se ligar e destruir células infectadas por vírus e células tumorais ${ }^{12}$. A deficiência grave do AF está associada com o declínio da atividade dessas células ${ }^{19}$. 
886 | S.K. UEHARA \& G. ROSA

Nas células neoplásicas, a replicação do DNA e a divisão celular ocorrem rapidamente. A deficiência do AF ou alterações no metabolismo dessa vitamina prejudica a síntese de DNA, inibindo o crescimento do tumor e a progressão de células neoplásicas pré-existentes. Esse é o mecanismo de ação do metotrexato, utilizado no tratamento do câncer ${ }^{20}$.

O metotrexato inibe a enzima di-hidrofolato redutase e depleta o tetra-hidrofolato intracelular, prejudicando a síntese de timidilato e, consequentemente, a de DNA. As células tumorais podem desenvolver resistência ao metotrexato, sendo necessárias doses dez vezes maiores. Nesse caso, é necessária a suplementação com AF a fim de inibir a transformação de células normais em tumorais. A deficiência do AF em tecidos normais os predispõe à transformação neoplásica. Além disso, a suplementação com AF protege o organismo dos efeitos adversos do metotrexato, tais como depressão da medula óssea e danos ao epitélio do sistema gastrointestina| ${ }^{20}$.

Estudos apontam também para uma provável influência do $A F$ na redução do peso. 21,22 Martinez et al. ${ }^{21}$ acompanharam, durante um ano, 182 pacientes com obesidade grau 3 submetidos a um programa para redução do peso baseado nas mudanças do estilo de vida (dieta baseada no consumo de frutas, hortaliças e grãos integrais e atividade física) e no tratamento farmacológico. Ao final do estudo, 21 pacientes (11,5\%) apresentaram uma redução de $10 \%$ do peso inicial, atingindo o objetivo do programa. Entre participantes desse estudo, observou-se a associação entre as concentrações séricas de AF e ferritina com a perda de peso. Além disso, os pacientes que iniciaram o estudo com altas concentrações séricas de AF apresentaram 8,5 vezes mais chances de redução de peso do que aqueles com baixas concentrações. Assim, o AF sérico parece ser um preditor de perda de peso.

Ortega et al. ${ }^{22}$ investigaram 67 mulheres com sobrepeso e em idade reprodutiva que foram distribuídas aleatoriamente em dois grupos. Os grupos foram submetidos à dieta energética; um grupo foi orientado a aumentar a ingestão de frutas e hortaliças e o outro, o consumo de alimentos enriquecidos com AF (cereais matinais). Os dois grupos apresentaram redução de peso, aumento na ingestão de AF dietético, aumento nas concentrações séricas de AF e redução da homocisteinemia. Contudo, os melhores resultados foram observados no grupo que consumiu cereais matinais. A menor biodisponibilidade do AF presente nos alimentos poderia explicar os resultados obtidos.

\section{Ácido fólico e o processo reprodutivo}

Pesquisas científicas sugerem que o AF desempenhe importante papel no processo reprodutivo, sendo sua deficiência associada à infertilidade masculina e à feminina. Essa relação pode ser explicada por meio do importante papel do AF na síntese e metilação de DNA, na prevenção da Hhcy e na defesa contra os radicais livres ${ }^{14,23}$.

A síntese e a metilação de DNA são fundamentais para a gametogênese, o que explicaria a elevada frequência do polimorfismo C677T no gene MTHFR entre os homens estéreis. Esse polimorfismo prejudica a síntese de SAM e, consequentemente, a metilação do DNA ${ }^{14}$.

Nos homens, a Hhcy tem sido associada com o aumento da produção de citocinas inflamatórias (proteína quimiotática de monócitos - MCP-1 e interleucina 8 - IL-8) que causam inflamação testicular e redução das concentrações de óxido nítrico, necessária para a ereção peniana, espermatogênese, motilidade dos espermatozóides, fertilização e reação acrossômica. Nas mulheres, a IL-8 e o MCP-1 estão associados à endometriose, uma das causas mais comuns de esterilidade feminina, enquanto que baixas concentrações de óxido nítrico comprometeriam a ovulação e a implantação do óvulo ${ }^{14,23}$.

Os espermatozóides são particularmente susceptíveis aos danos da peroxidação lipídica, pois sua membrana possui grandes quantidades de ácidos graxos insaturados, alvos principais das 
EROs. Concentrações elevadas de ERO alteram a fluidez e a funcionalidade da membrana dos espermatozóides, prejudicando sua capacitação e, consequentemente, sua penetração no ovócito. Foi demonstrado que homens estéreis apresentam elevações nas concentrações das ERO no líquido seminal. Nas mulheres, o EO tem sido relacionado com a ocorrência de endometriose, abortos espontâneos, pré-eclâmpsia, diabetes gestacional e parto prematuro ${ }^{14,23}$.

Em humanos, dados sobre os efeitos da nutrição na fertilidade são escassos. A suplementação com AF parece aumentar a contagem de espermatozóides em homens com problemas de fertilidade. Contudo, a suplementação conjunta com zinco parece potencializar o efeito do AF. A participação do zinco no metabolismo do AF explicaria esse resultado. Mulheres suplementadas com AF apresentam concentrações reduzidas de hcy no fluido folicular e ovócitos de melhor qualidade e com maior grau de maturação quando comparadas às não suplementadas ${ }^{14}$.

A Hhcy tem sido relacionada com as complicações durante a gestação, tais como pré-eclâmpsia, ruptura da placenta, retardo no crescimento intrauterino, baixo peso ao nascer, parto prematuro, abortos, morte fetal intrauterina e DTN, como anencefalia e espinha bífida ${ }^{5}$.

As reservas corporais adequadas do AF no período periconcepcional e nas quarta e oitava semanas gestacionais, período crítico do desenvolvimento embrionário, estão relacionadas com menor risco de má-formações do sistema nervoso central. A deficiência do AF prejudica a divisão celular e a síntese de DNA, resultando em má-formação do SNC e DTN24. O polimorfismo C677T no gene MTHFR é considerado fator de risco para os DTN ${ }^{5}$. Salienta-se que a anencefalia e a espinha bífida ocorrem quando o tubo neural do embrião sofre uma falha em seu fechamento entre o $22^{\circ}$ e $28^{\circ}$ dias após a concepção, período no qual a maioria das mulheres desconhece o seu estado gestacional ${ }^{23}$.

Considerando as evidências que associam a deficiência de AF com a ocorrência dos DTN, recomenda-se a suplementação de $400 \mu \mathrm{g} /$ dia de $A F$, além da quantidade contida nos alimentos, para as mulheres em idade fértil no período pré-concepção por um mês e pós-concepção por 2 meses $^{24}$. Para as mulheres que já tiveram um filho com DTN, a dose recomendada do AF é de $4.000 \mu \mathrm{g} / \mathrm{dia}$, sendo a suplementação iniciada um mês antes da concepção e mantida até o $3^{\circ}$ mês da gestação ${ }^{24,25}$. Tendo em vista as evidências sobre o papel protetor do AF na prevenção e ocorrência dos DTN, os alimentos fontes de AF são considerados alimentos funcionais ${ }^{26}$.

Segundo a literatura científica, existe uma associação entre o polimorfismo C677T no gene da MTHFR, o metabolismo do AF, a metilação do DNA e a síndrome de Down (SD) ${ }^{25}$. A hipometilação do DNA, decorrente do metabolismo anormal do AF associado aos polimorfismos no gene da MTHFR, está relacionada com falhas na disjunção do cromossomo 21 na meiose I materna ${ }^{27}$. Mães de crianças com SD tendem a apresentar aumento da homocisteinemia, tendo sido verificada a transferência de hcy para o feto através da placenta, o que sugere uma possível influência da Hhcy na etiologia da SD ${ }^{28}$.

\section{Epidemiologia da deficiência de ácido fólico}

Conforme citado por Santos \& Pereira ${ }^{29}$, o alcance dos requerimentos do AF por meio da dieta balanceada, sem a inclusão de alimentos fortificados e suplementos, é dificil, uma vez que ela fornece aproximadamente $0,25 \mathrm{mg} /$ dia dessa vitamina, considerando o valor energético total de cerca de $2200 \mathrm{kcal} / \mathrm{dia}$. A dificuldade aumenta devido à menor biodisponibilidade do AF natural dos alimentos e à baixa ingestão dietética de alimentos-fonte dessa vitamina ${ }^{29}$. No Brasil, dados da Pesquisa de Orçamento Familiar (POF 2002 - 2003) revelaram que a dieta dos brasileiros era rica em açúcares (refrigerantes) e pobre em frutas e hortaliças ${ }^{30}$.

Na literatura, dispomos de dados da população brasileira que demonstraram estado nutri- 
888 | S.K. UEHARA \& G. ROSA

cional inadequado do AF em adolescentes ${ }^{31,32}$, mulheres em idade fértil ${ }^{32}$ e gestantes adul$\operatorname{tas}^{24,33,34,35}$ e adolescentes ${ }^{36,37}$, grupos populacionais considerados de risco para a deficiência dessa vitamina.

No Brasil, Vitolo et al. ${ }^{32}$ avaliaram, pela primeira vez, o consumo alimentar de AF de adolescentes $(n=722)$. A frequência de adolescentes com risco de ingestão do AF abaixo da estimativa de requerimento médio (EAR) foi de $89 \%$. Esse comportamento foi associado com a maior faixa etária, circunferência da cintura maior do que o percentil 80 e com o baixo consumo de feijão e vegetais verdes-escuros. Outro estudo brasileiro ${ }^{31}$ investigou a hipótese de que adolescentes com sobrepeso apresentavam maiores concentrações de hcy plasmática do que os adolescentes sem sobrepeso. Além disso, os autores avaliaram a associação da homocisteinemia com as concentrações séricas de AF e cobalamina, glicose, insulina, resistência à insulina e perfil lipídico, em ambos os grupos. Não houve diferença significativa nas concentrações de hcy, AF e cobalamina entre os adolescentes com e sem sobrepeso. Ambos os grupos apresentaram valores médios de hcy elevados (com sobrepeso: 11,8 $\mu \mathrm{mol} / \mathrm{L}$ e sem sobrepeso: 11,6 $4 \mathrm{~mol} / \mathrm{L})$. A deficiência do AF $(<5 \mathrm{ng} / \mathrm{mL}$ ) foi observada nos dois grupos, sendo identificada em 68,6\% dos adolescentes investigados. A idade, o sexo e o AF sérico foram os determinantes da homocisteinemia.

Rosa ${ }^{33}$ avaliou a homocisteinemia em muIheres brasileiras adultas em idade reprodutiva (não gestantes e não nutrizes) $(n=50)$, com baixa ingestão habitual do AF, e sua relação com o Folato em Eritrócitos (FE), Folato Plasmático (FP), cobalamina plasmática, tabagismo, consumo de bebidas alcoólicas e cafeína, parturação, Índice de Massa Corporal (IMC) e uso de contraceptivos orais. A homocisteinemia média foi de 15,5 $\mathrm{mol} / \mathrm{L}$; $48 \%$ das mulheres apresentaram Hhcy, o que pode ser preditor para as DCV e fator de risco para complicações em futuras gestações. Além disso, 57\% e 46\% do grupo apresentaram depleção de $\mathrm{FE}$ e $\mathrm{FP}$, respectivamente. A ingestão habitual do AF por essas mulheres foi de $288 \mu \mathrm{g} / \mathrm{dia}$, valor abaixo da recomendação nutricional de $400 \mu \mathrm{g} /$ dia. O estado nutricional de AF foi o principal determinante da homocisteinemia no grupo estudado 33 .

No Brasil, estudo realizado por Rosa et al. ${ }^{34}$ avaliou as modificações da homocisteinemia durante a gestação ( $1^{\circ}$ e $3^{\circ}$ trimestres) e no pós-parto em uma coorte de mulheres adultas $(n=46)$, rotineiramente suplementadas com AF durante a gestação. Além disso, foi investigada a relação da homocisteinemia com os indicadores do estado nutricional do AF e da cobalamina, fatores dietéticos, parturação, complicações, desenvolvimento e resultado da gestação, tabagismo, uso de bebidas alcoólicas e IMC pré-gestacional. Verificou-se que $96 \%$ apresentavam consumo de AF menor do que a recomendação nutricional para as gestantes, que é de $600 \mu \mathrm{g} / \mathrm{dia}$. Durante a gestação, houve uma redução da homocisteinemia, tendo sido observada, no pós-parto, uma elevação ( $1^{\circ}$ trimestre: $10,3 \mu \mathrm{mol} / \mathrm{L}, 3^{\circ}$ trimestre: $8,7 \mu \mathrm{mol} / \mathrm{L}$ e pós-parto: $11,6 \mu \mathrm{mol} / \mathrm{L})$. Durante a gestação, verificou-se um aumento do FE e FP, provavelmente devido à suplementação com $A F$, enquanto no pós-parto, observou-se uma redução. Baixas concentrações de FE e FP foram observadas em sete e cinco mulheres respectivamente no primeiro trimestre ${ }^{34}$. Esses resultados são preocupantes, uma vez que o estabelecimento dos diversos tipos de má-formações fetais, decorrentes da deficiência do $A F$, ocorre entre o $22^{\circ}$ e $28^{\circ}$ dias (defeitos no tubo neural), $36^{\circ}$ dia (lábio leporino), $42^{\circ}$ dia (defeitos do septo ventricular cardíaco) e entre o $47^{\circ}$ e $72^{\circ}$ dias (fenda palatina) após a concepção ${ }^{25}$.

Nogueira et al. ${ }^{36}$ avaliaram o estado nutricional do AF e zinco, bem como o impacto nas concentrações plasmáticas desses micronutrientes, após diferentes esquemas de suplementação, em 74 gestantes adolescentes brasileiras. Nesse estudo, as gestantes foram aleatoriamente distribuídas em cinco grupos. Os grupos I e II receberam quantidades similares do AF $(250 \mu \mathrm{g})$ e diferentes concentrações de sulfato ferroso (120 
e $80 \mathrm{mg}$, respectivamente). Os grupos III e IV receberam quantidades iguais do AF $(250 \mu \mathrm{g})$ associado com sulfato de zinco ( $5 \mathrm{mg}$ ) e ferro nas concentrações de 120 e $80 \mathrm{mg}$ respectivamente. O grupo $V$ recebeu apenas sulfato ferroso (120mg). Verificou-se que $37 \%$ e $79 \%$ das gestantes adolescentes apresentaram concentrações plasmáticas reduzidas de AF e zinco respectivamente. $\mathrm{O}$ uso combinado de ferro/AF e ferro/AF/zinco promoveu a melhora da deficiência do AF, sendo esse efeito mais expressivo nos grupos que receberam AF associado ao zinco, o que suge-re uma possível participação do zinco no aproveitamento dessa vitamina ${ }^{36}$.

\section{Enriquecimento dos alimentos com ácido fólico}

Atualmente, aproximadamente quarenta países, sendo a maioria da América do Sul e, em menor proporção, da África e Ásia, tornaram obrigatória a fortificação da farinha de trigo com $\mathrm{AF}^{37}$. No Brasil, essa prática foi adotada desde junho de 2004. Em 2002, a Agência de Vigilância Sanitária (ANVISA), por meio da Resolução $n^{\circ} 344$, determinou a obrigatoriedade da fortificação das farinhas de trigo e milho com AF e ferro no Brasil. Segundo a legislação, cada 100 gramas de farinhas de milho e trigo deverão conter, no mínimo, $4,2 \mathrm{mg}$ de ferro e $150 \mu \mathrm{g}$ de AF. As embalagens dessas farinhas deverão informar, além do nome convencional do produto, segundo a legislação específica, uma das seguintes expressões: a) fortificada com ferro e $A F$, b) enriquecida com ferro e $A F$ e c) rica em ferro e $A F^{39}$.

Estudos realizados no Chile ${ }^{40}$ e Canadá 41 demonstraram uma diminuição na incidência de DTN após o enriquecimento da farinha de trigo com AF. Yang et al. ${ }^{41}$ demonstraram uma redução da mortalidade por acidente vascular encefálico após a fortificação de alimentos com AF no Canadá e nos Estados Unidos. A melhora do estado do AF e a redução da homocisteinemia observadas nesse estudo poderiam explicar o resultado.
Embora já esteja aprovada a normativa de obrigatoriedade da fortificação das farinhas de milho e trigo com AF e ferro no Brasil, estudo realizado por Boen et al. ${ }^{43}$ investigou o conteúdo de AF e ferro nas farinhas de trigo disponíveis no comércio da cidade de Campinas (SP). Observou-se que a maioria das amostras apresentou quantidades acima ou abaixo dos valores previstos para ferro $(4,2 \mathrm{mg} / 100 \mathrm{~g})$ e para $\operatorname{AF}(150 \mu \mathrm{g} / 100 \mathrm{~g})^{42}$.

O valor limite superior tolerável de ingestão (UL) recomendado para o AF é de $1 \mathrm{mg} /$ dia para adultos. Convém destacar que doses elevadas de AF podem dificultar o diagnóstico da anemia perniciosa e de outras manifestações decorrentes da deficiência de cobalamina, contribuindo para o desenvolvimento de danos neurológicos progressivos e irreversíveis ${ }^{43}$. Esse problema poderia ser resolvido com a fortificação dupla dos alimentos com cobalamina e $\mathrm{AF}^{38}$.

Santos \& Pereira ${ }^{29}$ sugeriram que apenas a fortificação das farinhas de trigo e milho não seja suficiente para aumentar a ingestão do $\mathrm{AF}$, uma vez que, segundo a POF (2002 - 2003), para os produtos farináceos encontrados com frequência apreciável, a disponibilidade média diária domiciliar foi de 106,1g. Essa quantidade permitiria uma oferta adicional de AF de $0,16 \mathrm{mg} / \mathrm{dia}$, considerando o conteúdo da fortificação regulamentada. Destaca-se que, dependendo da região analisada, varia a aquisição domiciliar média de produtos farináceos: no Sul, esse valor é de 144g/dia, contribuindo com cerca de $0,217 \mathrm{mg}$ de $\mathrm{AF}$; no Norte e Centro-Oeste, o consumo foi de $70 \mathrm{~g} / \mathrm{dia}$ e a oferta de AF menor do que $0,1 \mathrm{mg}^{30,39}$.

Embora o leite e seus derivados não sejam boas fontes do $\mathrm{AF}$, esses alimentos apresentam proteínas ligantes dessa vitamina que estão envolvidas com a biodisponibilidade do AF. Por isso, o leite e seus derivados parecem ser uma boa alternativa para a fortificação com AF, podendo ser utilizados para aumentar a ingestão dessa vitamina ${ }^{43}$.

Pacheco et al..$^{44}$ investigaram o efeito da fortificação de alimentos com AF na prevalência de defeito do fechamento do tubo neural entre 
nascidos vivos do município do Recife entre 2000 e 2006 e não observaram diferença significativa na prevalência desse evento, nos períodos anterior e posterior à fortificação. No entanto, esses resultados não permitem descartar o benefício dessa fortificação na prevenção dessa má-formação, sendo necessários estudos realizados num maior intervalo de tempo e que considerem o consumo dos produtos fortificados pelas mulheres em idade fértil.

Tanya et al. ${ }^{45}$ demonstraram limitações da estratégia da fortificação dos alimentos com $\mathrm{AF}$, como medida isolada, para prevenção de má-formações. Avaliaram o incremento da ingestão de AF durante o período mandatório de fortificação nos Estados Unidos e observaram um aumento de apenas $100 \mu \mathrm{g} / \mathrm{dia}$ no consumo dessa vitamina na população. Também observaram um aumento de 26 a 38\% de mulheres em idade fértil que atingiam a recomendação de $400 \mu \mathrm{g} / \mathrm{dia}$ do AF. Adicionalmente, foi demonstrada uma redução média entre 20 e 30\% na prevalência de defeitos no fechamento do tubo neural, após a adoção da política de fortificação.

Em 2005, a Associação Brasileira de Epilepsia (ABE) realizou pesquisa com o objetivo de avaliar o grau de conhecimento das mulheres em geral e gestantes sobre a importância do $\mathrm{AF}^{25}$. Os resultados da pesquisa que contemplou 90 mulheres revelaram que $42 \%(n=38)$ já tinham ouvido falar sobre o AF; $21 \%(n=19)$ sabiam da importância do $A F$, mas apenas $10 \%(n=9)$ receberam essa informação pelo médico; $13 \%(n=12)$ sabiam da distribuição do AF na rede pública de saúde e $13 \%(n=12)$ não se preocupavam com a alimentação.

O desconhecimento das mulheres sobre a importância do AF na prevenção de resultados indesejáveis na gestação e o não cumprimento da lei de fortificação de farinhas de milho e de trigo com AF e ferro são dados preocupantes que reforçam a necessidade de promover campanhas educativas e fiscalizar o processo de adição de AF e de ferro nas farinhas.
Adicionalmente, é necessária a realização de estudos epidemiológicos que avaliem o impacto do enriquecimento de alimentos com AF no estado nutricional dessa vitamina nos grupos populacionais considerados de risco.

No Brasil, até o momento, não foi avaliada a fortificação das farinhas de trigo e milho com AF. Apenas um programa paulista, do município de São Paulo, investigou o cumprimento da fortificação conforme a legislação vigente. Foram analisadas 85 amostras do comércio varejista, tendo sido observadas $14 \%$ com quantidades insatisfatórias, isto é, abaixo do limite mínimo estabelecido ${ }^{46}$.

\section{Suplementação medicamentosa com ácido fólico}

O AF dietético, sob a forma de poliglutamato, deve ser convertido em monoglutamato para ser absorvido. Ao contrário, o AF sob a forma de suplemento medicamentoso é mais estável e se encontra na forma de monoglutamato, que é rapidamente absorvido. A biodisponibilidade do AF dietético para a absorção intestinal é de aproximadamente $60 \%$ e a do utilizado nos suplementos é de $98 \%$. Desse modo, a suplementação com AF parece ser mais eficiente na prevenção da deficiência nutricional dessa vitamina'.

Convém destacar que, antes de iniciar o tratamento com a suplementação com AF, deve-se avaliar o estado nutricional de cobalamina e, nos casos de deficiência dessa vitamina, deve-se administrar simultaneamente o AF e a cobalamina, pois a suplementação com AF em indivíduos com deficiência de cobalamina poderá resultar em alterações neurológicas ${ }^{9}$.

Como consequência da normalização da hematopoiese, após a suplementação com AF, pode-se observar uma diminuição nas concentrações de potássio sérico (1-2mEq/dL em 48 horas), sendo necessário em alguns casos a suplementação desse eletrólito. 
Também quando se corrige a deficiência primária de AF podemos contribuir com o rápido consumo de ferro, sendo às vezes necessária a suplementação simultânea desse mineral com o $\mathrm{AF}^{1}$.

Apesar das evidências de redução da ocorrência de má-formações durante a gestação, alguns autores questionam o efeito protetor isolado da fortificação de alimentos com AF, defendendo a instituição de diferentes estratégias para a promoção do aumento da ingestão dessa vitamina durante a gestação, como, por exemplo, a associação da suplementação periconcepcional com a fortificação de alimentos e o estímulo ao consumo de alimentos que sejam fonte de $\mathrm{AF}^{5}$.

\section{Polimorfismos no gene que codifica a enzima metilenotetra-hidrofolato redutase (MTHFR)}

O metabolismo do AF envolve mais de 30 genes, sendo o mais estudado o polimorfismo C677T no gene MTHFR. Esse polimorfismo consiste na substituição da Citosina (C) pela Timina ( $T$ ) no Nucleotídeo 677, no éxon 4 do gene que codifica a MTHFR. Essa substituição de bases nitrogenadas resulta na tradução do aminoácido valina ao invés de alanina, originando uma enzima termolábil com menor capacidade catalítica e estabilidade in vitro.

Os indivíduos com o polimorfismo em ambos os alelos (genótipo TT) apresentam uma redução de $70 \%$ e em um alelo (genótipo CT), de $35 \%$ da atividade da enzima MTHFR quando comparados àqueles sem o polimorfismo (genótipo (C) ${ }^{1}$.

Em comparação com os indivíduos sem o polimorfismo C677T no gene MTHFR, as concentrações plasmáticas de homocisteína entre os que apresentam esse polimorfismo são 25\% maiores, bem como são baixas as concentrações plasmáticas de AF. A influência genética desse polimorfismo sobre a homocisteinemia não é significativa nos indivíduos que apresentam estado nutricional de AF e cobalamina adequados. $\mathrm{O}$ aumento das concentrações plasmáticas de homocisteína tem sido atribuído à presença do polimorfismo C677T no gene MTHFR, principalmente quando associado a baixas concentrações de AF e cobalamina plasmáticas. Desse modo, os indivíduos que apresentam esse polimorfismo necessitam de um maior requerimento de AF para prevenir a hiperhomocisteimenima. Nesse caso, a suplementação com AF pode ser necessária².

Uehara \& Rosa ${ }^{47}$ realizaram estudo transversal para investigar a associação da hcy com componentes da síndrome metabólica, indicadores do estado nutricional de AF e cobalamina, polimorfismo C677T no gene MTHFR, outros biomarcadores e estilo de vida, sendo observada associação positiva entre a uricemia $(C=0,67$, $\left.\chi^{2}=2,23, p=0,27\right)$, insulinemia $\left(C=0,86, \chi^{2}=2,98\right.$, $p=0,07)$ e o risco de desenvolver a hiper-homocisteinemia. Não foi verificada associação entre o polimorfismo C677T com a homocisteinemia, provavelmente devido ao adequado estado nutricional de AF observado no grupo estudado.

O segundo polimorfismo mais estudado é o A1298C, que consiste na substituição da base adenina pela citosina, que resulta na substituição do aminoácido glutamato pela alanina no gene MTHFR. Evidências científicas comprovam que, na presença dos polimorfismos C677T e A1298C no gene MTHFR, a atividade da MTHFR é reduzida em dois terços. Por outro lado, não há relatos que o polimorfismo A1298C isoladamente possa promover um aumento nas concentrações de homocisteína plasmática ou alterar as concentrações plasmáticas de $\mathrm{AF}^{41}$.

\section{CONSIDERAÇÕ ES FINAIS}

Em 2001, a Agência Nacional de Vigilância Sanitária (ANVISA), com o objetivo de normatizar a fortificação das farinhas de trigo e milho, abriu consulta pública na qual foi sugerida a inclusão da fortificação com AF, objetivando reduzir os defeitos do tubo neural. No entanto, considerando os dados da POF de 1995-1996 versus 2002-2003, observou-se que houve uma redução no consumo per capita em domicílio da farinha de trigo de 3,1 para 2,6, de farinha de milho de 
892 | S.K. UEHARA \& G. ROSA

1,7 para 1,3 e do pão francês de 18,4 para 17,8. Isso poderia reduzir o impacto dessa fortificação, sendo necessária a implementação concomitante de outras estratégias para que o objetivo seja alcançado.

O governo brasileiro até o momento não realizou a avaliação da fortificação das farinhas de trigo e de milho com AF junto às indústrias alimentícias. Temos conhecimento de uma iniciativa isolada de um programa paulista (2006), do município de São Paulo, que avaliou o cumprimento da fortificação conforme a legislação vigente. Foram analisadas 85 amostras do comércio varejista, tendo sido observadas $14 \%$ delas com quantidades insatisfatórias, isto é, abaixo do limite mínimo estabelecido.

Deve-se investigar, considerando os hábitos alimentares regionais, o baixo consumo de alimentos fortificados pela população e comparar o consumo do AF antes e após a fortificação obrigatória no Brasil a fim de avaliar sua eficácia na prevenção de má-formações na gestação e outras doenças.

Portanto, evidências científicas que relatam a interação entre as características genéticas, o padrão alimentar, a prevalência de doenças crônicas não-transmissíveis, a fortificação alimentar e o uso de suplementos com AF sem a realização de um diagnóstico nutricional prévio demonstraram a ocorrência de situações patológicas em alguns grupos populacionais, como mulheres em idade fértil, gestantes e idosos. É de suma importância a realização de estudos de base populacional para análise do estado nutricional do AF, dos polimorfismos associados a essa vitamina, a fim de gerar subsídios para elaboração de estratégias governamentais, mais adequadas e eficazes. Destaca-se ainda a necessidade da reeducação nutricional para população brasileira a fim de aumentar o consumo de alimentos fontes do ácido fólico.

\section{A GRADECIMENTO}

À Fundação de Amparo à Pesquisa (FAPERJ) o apoio financeiro para a realização desse trabalho.

\section{COLABORADORES}

S.K. UEHARA elaborou os itens: métodos, absorção e aspectos fisiológicos do ácido fólico, ácido fólico e o processo reprodutivo, suplementação medicamentosa com ácido fólico e polimorfismos no gene que codifica a enzima MTHFR. G. ROSA escreveu os itens: introdução, ácido fólico e sua associação com as doenças crônicas não-transmissíveis, epidemiologia da deficiência do ácido fólico, enriquecimento dos alimentos com ácido fólico e considerações finais.

\section{REFERÊ NCIAS}

1. Martinez CA, Northrup $H$, Lin Jl, Morrison AC, Fletcher JM, Tyerman GH, et al. Genetic association study of putative functional single nucleotide polymorphisms of genes in folate metabolism and spina bifida. Am J Obstet Gynecol. 2009; 201(4): 394-411. doi:10.1016/j.ajog.2009.06.042.

2. DiBello PM, Dayal S, Kaveti S, Zhang D, Kinter M, Lentz SR, et al. The Nutrigenetics of hyperhomocysteinemia. Mol Cel Proteomics. 2010; 9:471-85. doi: 10.1074/mcp.M900406-MCP200.

3. Sturm I, Hennermann JB, von Arnim-Baas A, Driever $\mathrm{PH}$, Massenkeil G. Thromboembolic events, abortions and a sick infant- unusual presentation of a vitamin deficiency. Internist. 2008; 49(12): 1507-11. doi: 10.1007/s00108-008-2170-4.

4. Casas JP, Bautista LE, Smeeth L, Sharma P, Hingorani A. Homocysteine and stroke: evidence on a causal link from mendelian randomisation. Lancet. 2005; 365, 224-32. doi: 10.1016/S0140-6736(05)17742-3.

5. McGuire M, Cleary B, Sahm L, Murphy DJ. Prevalence and predictors of periconceptional folic acid uptake - prospective cohort study in an Irish urban. Hum Reprod. 2010; 25(2):535-43. doi:10.1093/humrep/dep398.

6. Wright AJA, Dainty JR, Finglas PM. Folic acid metabolism in human subjects revisited: potencial implications for proposed mandatory folic acid fortification in the US. Br J Nutr. 2007; 98(4): 667-75. doi:10.1017/S0007114507777140.

7. Bazzano LA. Folic acid supplementation and cardiovascular disease: the state of the art. Am J Med Sci . 2009; 338(1):48-9. doi: 10.1097/MAJ.0b 013 e3181aaefd6.

8. Pintó X, Vilaseca MA, Balcells S, Artuch R, Corbella $\mathrm{E}$, Meco JF, et al. A folate-rich diet is as effective as folic acid from supplements in decreasing plasma homocysteine concentrations. Int J Med Sci. 2005; 2(2):58-63 
9. Morris MS, Jacques PF, Selhub J. Relation between homocysteine and B-vitamin status indicators and bone mineral density in older Americans. Bone. 2005; 37: 234-42. doi: 10.1016/j.bone.2005.04. 017.

10. Schdey P. Homocisteína e transtornos psiquiátricos. Rev Bras Psiquiatr. 2004; 26(1):50-6. doi: 10.1590/ S1516-44462004000100013.

11. Rytter E, Vessby B, Asgård R, Johansson C, Sjödin A , Abramsson-Zetterberg L, et al. Glycaemic status in relation to oxidative stress and inflammation in well-controlled type 2 diabetes subjects. Br J Nutr. 2009; 101(10):1423-6.

12. Ebbing M, Bønaa KH, Nygård O, Arnesen E, Ueland PM, Nordrehaug JE, et al. Cancer incidence and mortality after treatment with folic acid and vitamin $B_{12}$. JAMA. 2009; 302(19): 2119-26. doi:10.1001/ jama.2009.1622.

13. Duthei SJ, Horgan G, de Roos B, Rucklidge G, Reid $M$, Duncan $G$, et al. Blood folate status and expression of protein involved in immune function, inflammation, and coagulation: biochemical and proteomic changes in the plasma of humans in response to long-term synthetic folic acid supplementation. J Proteome Res. 2010; 9(4): 1941-50.

14. Ebisch IMW, Thomas CMG, Peters WHM, Braat DDM, Steegers-Theunisse RPM. The importance of folate, zinc and antioxidants in the pathogenesis and prevention of subfertility. Hum Reprod Update. 2007; 13(2):163-74. doi:10.1093/humupd/ dml054.

15. Chanson A, Rock E, Martin JF, Liotard A, Brachet P. Preferential response of glutathione-related enzymes to folate-dependent changes in the redox state of rat liver. Eur J Nutr. 2007; 46(4):204-12. doi.org/101007/S00394-007-0651-1.

16. Song $Y$, Cook NR, Albert CM, Van Denburgh $M$, Manson JE. Effect of homocysteine-lowering treatment with folic Acid and B vitamins on risk of type 2 diabetes in women: a randomized, controlled trial. Diabetes. 2009; 58(8):1730-1. doi: 10.2337/db09-0087.

17. Tchantchou F, Shea TB. Folate deprivation, the methionine cycle, and Alzheimer's disease Vitam Horm. 2008; 79:83-97. doi:10.1016/S0083-6729 (08)00403-2.

18. Wani NA, Hamid A, Kaur J. Folate status in various pathophysiological conditions. Life. 2008; 60(12): 834-42. doi: 10.1002/iub.133.

19. Wu X, Liang Z, Zou T, Wang X. Effects of folic acid deficiency and MTHFRC677T polymorphisms on cytotoxicity in human peripheral blood lymphocytes. Biochem Biophys Res Commun.
2009; 379(3):732-7. doi:10.1016/j.bbrc.2008. 12.130.

20. Novakovic P, Stempak JM, Sohn KJ, Kim YI. Effects of folate deficiency on gene expression in the apoptosis and cancer pathways in colon cancer cells. Carcinogenesis. 2006; 27(5):916-24. doi:10. 1093/carcin/bgi312.

21. Martinez JJG, Ruiz FA, Candil SD. Baseline serum folate level may be a predictive factor of weight loss in a morbid-obesity-management programme. Br J Nutr. 2006; 96(5):956-64.

22. Ortega RM, López-Sobaler AM, Andrés $P$, Rodríguez-Rodríguez E, Aparício A, Bermejo LM, et al. Changes in folate status in overweight/obese women following two different weight control programmes based on an increased consumption of vegetables or fortified breakfast cereals. Br J Nutr. 2006; 96(4):712-8.

23. Forges T, Monnier-Barbarino P, Alberto JM, GuéantRodriguez RM, Daval JL, Guéant JL. Impact of folate and homocysteine metabolism on human reproductive health. Hum Reprod Update. 2007; 13(3):225-38. doi:10.1093/humupd/dml063.

24. Dary O. Nutritional interpretation of folic acid interventions. Nutr Rev. 2009; 67(4): 235-44. doi:10.1111/j.1753-4887.2009.00193.x.

25. Nasser C, Nobre C, Mesquita S, Ruiz JG, Carlos $H R$, Prouvot $L$, et al. Semana da conscientização sobre a importância do ácido fólico. J Epilepsy Clin Neurophysiol. 2005;11(4):199-203. doi: 10.1590/ S1676-26492005000400009.

26. American Dietetic Association. Position of the American Dietetic Association: Functional Foods. J Am Diet Assoc. 2004; 104(5):814-26. doi:10.1016/ j.jada.2004.03.015.

27. Patterson D. Folate metabolism and the risk of Down syndrome. Downs Syndr Res Pract. 2008; 12(2):93-7. doi:10.3104/updates.2051.

28. Silva LRJ, Vergani N, Galdieri LC, Porto MPR, Longhitano SN, Brunoni D, et al. Relationship between polymorphisms in genes involved in homocysteine metabolism and maternal risk for Down syndrome in Brazil. Am J Med Genet. 2005; 135:263-7. doi:10.1002/ajmg.a.30591.

29. Santos LMP, Pereira MZ. Efeito da fortificação com ácido fólico na redução dos defeitos do tubo neural. Cad Saúde Pública. 2007; 23(1):17-24. doi: 10.1590/S0102-311X2007000100003.

30. Instituto Brasileiro de Geografia e Estatística. Pesquisa de Orçamentos Familiares (POF): análise de disponibilidade domiciliar de alimentos e do estado nutricional no Brasil. Rio de Janeiro: IBGE; 2004 [acesso 2009 dez 6]. Disponível em: <http://www. ibge.gov.br/home/presidencia/noticias/noticia_ impressao.php?id_noticia=278>. 
894 | S.K. UEHARA \& G. ROSA

31. Brasileiro RS, Escrivão MAMS, Taddei JAAC, D'Almeida V, Ancona-Lopez F, Carvalhaes JTA. Plasma total homocysteine in Brazilian overweight and non-overweight adolescents: a case-control study. Nutr Hosp. 2005; 20(5):313-9.

32. Vitolo MR, Canal Q, Campagnolo PDB, Gama CM. Factors associated with risk low folate intake among adolescents. J Pediatr. 2006; 82(2):121-6.

33. Rosa G. Relação da homocisteinemia com o estado nutricional de folato e outros determinantes em mulheres em idade reprodutiva e gestantes [tese]. Rio de Janeiro: Universidade Federal do Rio de Janeiro; 2003.

34. Rosa G, Pereira SEA, Trugo NMF. Longitudional change in plasma total homocysteine during pregnancy and postpartum in Brazilian women and its relation with folate status and other factors. Int J Vitam Nutr Res. 2004; 74(2):95-101.

35. Esmaillzadeh A, Samareh S, Azadbakht L. Dietary patterns among pregnant women in the westnorth of Iran. Pak J Biol Sci. 2008;11(5):793-6. doi: 10.3923/pjbs.2008.793.796.

36. Nogueira NN, Parente JV, Cozzolino SM. Changes in plasma zinc and folic acid concentrations in pregnant adolesce.nts submitted to different supplementation regimens Cad Saúde Pública. 2003; 19(1):155-60. doi: 10.1590/S0102-311X200 3000100017.

37. Moran VH. Nutritional status in pregnant adolescents: a systematic review of biochemical markers. Matern Child Nutr. 2007; 3(2):74-93.

38. Barros DC, Pereira RA, Gama SGN, Leal MC. O consumo alimentar de gestantes adolescentes no Município do Rio de Janeiro. Cad Saúde Pública. 2004; 20 (supl.1):S121-S9. doi: 10.1590/S0102-3 $11 \times 2004000700013$.

39. Agência Nacional de Vigilância Sanitária. RDC n. 344 , de 13 de dezembro de 2002. Aprova o regulamento técnico para a fortificação das farinhas de trigo e das farinhas de milho com ferro e ácido fólico. [acesso 2009 jan 16]. Disponível em: <http:// www.anvisa.gov.br/legis/resol/2002/344_02 rdc.htm>

40. Nazer HJ, Cifuentes OL, Aguila RA, Juarez HME, Cid RMP, Godoy VML et al. Efecto de la fortificación de la harina com ácido fólico sobre la evolución de las tasas de prevalencia al nacimiento de malformaciones congênitas en los hospitales chilenos Del ECLAMC. Rev Med Chil. 2007; 135(2): 198-204.

41. Yang Q, Botto LD, Erickson JD, Berry RJ, Sambell $C$, Johansen $\mathrm{H}$, et al. Improvement in stroke mortality in Canada and the United States, 1990 to 2002. Circulation. 2006; 113(10):1335-43. doi: 10.1161/CIRCULATIONAHA. 105.570846

42. Boen TR, Soeiro BT, Pereira Filho ER, Lima-Pallone JA. Folic acid and iron evaluation in Brazilian enriched corn and wheat flours. J Braz Chem Soc. 2008; 19(1):53-9. doi: 10.1590/S0103-505320 08 000100009.

43. Achanta K, Boeneke CA, Aryana KJ. Characteristics of reduced fat milks as influenced by the incorporation of folic acid. J Dairy Sci. 2007; 90 (1): 90-8.

44. Pacheco SS, Braga C, Souza Al, Figueiroa JN. Efeito da fortificação alimentar com ácido fólico na prevalência de defeitos do tubo neural. Rev Saúde Pública. 2009; 43(4):565-71. doi: 10.1590/S0034-8910 2009005000033.

45. Tanya GK, Willett WC, Weinstein MC, Kuntz KM. Populatio level changes in folate intake by age, gender and race/ethnicity after folic acid fortification. Am J Public Health. 2006; 96(11): 2040-7. doi: 10.2105/AJPH.2005.067371.

46. Schlindwein MM, Kassouf AL. Mudanças no padrão de consumo de alimentos tempo-intensivos e de alimentos poupadores de tempo, por região do Brasil. In: Gasto e consumo das famílias brasileiras contemporâneas. Brasília: IPEA; 2006-2007. v.2, p.423-462.

47. Uehara SK, Rosa G. Association of homocysteinemia with high concentrations of serum insulin and uric acid in Brazilian subjects with metabolic syndrome genotyped for C677T polymorphism in the methylenetetrahydrofolate reductase gene. Nutr Res. 2008; 28(11):760-6. doi:10.1016/j.nutres.2008.09.006.

Recebido em: 3/6/2008

Versão final reapresentada em: 24/5/2010 Aprovado em: 5/7/2010 